\title{
A la busca del colón perdido: modulaciones en torno a la figura del almirante en tres nuevas novelas históricas latinoamericanas
}

Diego Eduardo Niemetz*

Resumen: En este trabajo analizamos algunos de los modos en que la nueva novela histórica se relaciona con el material cronístico y documental. Tomamos como punto de referencia uno de los temas centrales de este fenómeno literario, el del descubrimiento y conquista de América, y nos centramos en la manera en que la figura de Cristóbal Colón es abordada por tres novelistas contemporáneos en sus producciones: El arpa y la sombra de Alejo Carpentier, Los perros del Paraíso de Abel Posse y El Conquistador de Federico Andahazi. Respetando una lienalidad cronológica, nos proponemos reflexionar sobre las diferentes modulaciones con que el material histórico y cronístico ha sido tratado por los escritores de ficción seleccionados, para comprender mejor cuáles son los modos en que la "historia" y la "literatura" se mixturan y se entrecruzan.

Palabras clave: Nueva novela histórica. Ficción. Crónica. Cristóbal Colón.

\footnotetext{
${ }^{*}$ Universidad Nacional de Cuyo - Conicet. Doutor em Letras. E-mail: diegoniemetz @gmail.com.
} 
A la busca del colón perdido: modulaciones en torno...

\section{Introducción}

[...] es menester advertir que el relato que va a leerse ha sido establecido sobre una documentación extremadamente rigurosa que no solamente respeta la verdad histórica de los acontecimientos, los nombres de personajes

- incluso secundarios -, de lugares y hasta de calles, sino que oculta, bajo su aparente intemporalidad, un minucioso cotejo de fechas y de cronologias. (Alejo Carpentier, El reino de este mundo, 1949. p. 7-8)

Desde un punto de vista socio-crítico, la ficción histórica experimentó un auge inusitado a partir de la segunda mitad del siglo XX. La infinidad de novelas que son publicadas bajo el rótulo de "novela histórica" ha generado uno de los episodios de la industria editorial más atendido por los críticos literarios en varias décadas. Basta con observar de modo superficial la lista, virtualmente interminable, de obras acogidas bajo esa clasificación para comprender las motivaciones que impulsaron a los profesores universitarios, historiadores de la literatura, periodistas culturales y críticos en general a producir un corpus de estudios que amenaza, por lo menos en un plano simbólico, a volverse casi tan inabarcable como el de las propias obras que se propone estudiar. Pero lo que resulta más interesante aún que esta ligera constatación cuantitativa, es el hecho (verificable también a partir de la misma consideración inicial sobre el corpus) de que el asunto despierta las más diversas reacciones y de que es objeto de apreciaciones contradictorias.

Fundamentalmente lo que Seymour Menton denominó "nueva novela histórica", es un fenómeno que se ha ido revelando cada vez más controversial no tanto en relación a su identificación, definición y valoración estética (aspectos, como veremos, también problemáticos) sino en relación a la especificidad de sus implicaciones en el plano ideológico. Para dejar en claro a qué movimiento socio-cultural nos referimos y cuáles son sus características, a nuestro entender, más importantes, resultan de gran utilidad las observaciones de María Cristina Pons cuando señala que:

En términos generales, esta novela histórica, tan en auge a fines del siglo XX, se caracteriza, ante todo, por una relectura 
crítica y desmitificadora que se traduce en una reescritura del pasado encarada de diverso modo: se problematiza la posibilidad de conocerlo y reconstruirlo, o se retoma el pasado histórico, documentado, sancionado y conocido, desde una perspectiva diferente, poniendo en descubierto mistificaciones y mentiras o, en un movimiento casi opuesto, se escribe para recuperar los silencios, el lado oculto de la historia, el secreto que ella calla (PONS, 2000, p. 97, resaltado nuestro).

Esta revisita al pasado desde la ficción, cuyo auge se asocia por un lado al aniversario por el quinto centenario del descubrimiento de América ${ }^{1}$ y, por otro lado, a la eclosión del período de las dictaduras latinoamericanas durante los 70 y $80^{2}$, como decíamos ha despertado numerosas y diversas reacciones por parte de los críticos. En este sentido, y si bien puede identificarse una gran mayoría de analistas que se muestran entusiasmados con la cantidad y calidad de la producción a la que nos estamos refiriendo, no es menos cierto (ni menos sintomático) que existe un número de estudiosos que observan el asunto con inocultable displicencia.

Entre los primeros debemos incluir al ya citado Seymour Menton, cuyo libro La nueva novela histórica de la América Latina, 1979-1992 se ha convertido, quizás, en el estudio más utilizado para abordar el tema. Se trata de un trabajo importante, en el cual se fijan algunas de las herramientas de análisis fundamentales para entender cuál es la especificidad del fenómeno, desde su aparición y desarrollo en una mirada estrictamente diacrónica hasta las características de corte pretendidamente intrínseco de este tipo de narración histórica. En este sentido, las consideraciones de Menton, aunque fundamentales, adolecen de una serie de imprecisiones y arbitrariedades que no siempre han sido tenidas en cuenta ni corregidas por sus seguidores. Otro autor que ha visto con profundidad $y$, al mismo tiempo, con evidente entusiasmo el desarrollo de la novelística histórica contemporánea es Fernando Aínsa, quien ha publicado otro libro fundamental sobre el tema, bajo el sugestivo título de Reescribir el pasado. El enfoque de Aínsa resulta de interés para nosotros porque gran parte de sus especulaciones se centran en evidenciar la importancia que ciertas manifestaciones históricas 
A la busca del colón perdido: modulaciones en torno...

o para-históricas tienen en el desarrollo de la nueva novela histórica. En otras palabras, ya que el descubrimiento y la conquista de América son uno de los motores fundamentales para la aparición y desarrollo de la nueva novela histórica, Aínsa ha estudiado las posibles líneas de continuidad que se establecen entre los relatos de los cronistas de los primeros tiempos y los novelistas del siglo XX y del XXI. El optimismo del crítico se hace evidente cuando asigna a esta nueva sensibilidad escrituraria un rol más democrático que el de la novela histórica anterior:

La nueva novela histórica al propiciar un acercamiento al pasado en actitud niveladora y dialogante, elimina la 'distancia épica' de la novela histórica tradicional y propicia una revisión crítica de los mitos constitutivos de la nacionalidad (AÍNSA, 2003, p. 28).

Esta revisión, en la cual la mirada consagrada de la historiografía clásica es cuestionada, es la que alienta a los críticos como Aínsa, Menton y Pons a señalar un período de "democratización de la memoria" que tendría, entre otros propósitos, el de saldar algunas de las cuentas del pasado, pero también el de denunciar la persistencia del genocidio en las prácticas represivas del presente. Por momentos el excesivo entusiasmo frente al fenómeno, les impide considerar las notables diferencias que existen entre los autores y las obras que conforman el corpus. La necesidad académica de historizar la aparición y evolución de la nueva novela histórica y de atarla a ciertas circunstancias extrínsecas ya mencionadas, como la proximidad del quinto centenario y la proliferación de regímenes dictatoriales, propician olvidos relativos a la disparidad ideológica $\mathrm{y}$, consecuentemente, a los objetivos y a las intenciones específicas de cada autor.

Sin embargo, como hemos adelantado, no todas las aproximaciones encuentran en el discurso contracultural de la nueva novela histórica un elemento auspicioso de apertura horizontal del relato histórico y democratización de la memoria. De hecho, algunos críticos insisten en advertir acerca de los peligros que conllevaría la manipulación ideológica de la que, según ellos, es objeto el material histórico.

Anos 90, Porto Alegre, v. 21, n. 40, p. 425-462, dez. 2014 
Así, en un trabajo en el que aborda la obra de Alejo Carpentier y de Abel Posse, Alicia Sarmiento advierte que:

La vuelta al pasado desde la contemporaneidad tampoco es inocente. Buena parte de la producción está signada por el materialismo y la utopía en sus más variadas versiones.... En todos los casos, la ideología confiere a la obra una carga operativa que trasciende el plano puramente estético o estrictamente histórico (SARMIENTO, 1989, p. 235, resaltado nuestro).

Es evidente en el fragmento copiado que la visión está dirigida a una práctica que, según la estudiosa, tiene raíces en el marxismo y en otras ideologías de izquierda. La advertencia sobre el presunto ideologismo de estos escritores frente a la, para nosotros sospechosa, neutralidad de otros autores que se apegan a la versión canónica del relato histórico es, de por sí, argumento suficiente para debilitar la crítica lanzada por Sarmiento y subrayar la intencionalidad revisionista de la nueva novela histórica como un mecanismo que intenta desnudar las solapadas prácticas de dominación empleadas el poder imperante. Resulta elocuente, por la reacción de ciertos sectores críticos, así como por las lecturas valorativas que se proponen desde instituciones que defienden una visión tradicional de, por ejemplo, el descubrimiento y la conquista de América, que la agresividad de la propuesta de la nueva narrativa histórica está lejos de ser una pasajera moda editorial y que, por el contrario, se ha convertido en un campo de batalla ideológico insoslayable ${ }^{3}$.

Como se desprende claramente de estas apretadas consideraciones, se trata de un hecho cultural extendido y complejo, que no admite ni una única lectura en lo tocante a su significado socio-histórico ni, mucho menos, una valoración unívoca en lo relativo a su calidad artística. Otra faceta que contribuye a complejizar el asunto es la cantidad de autores y obras, como así también su naturaleza estética, que componen el canon de nuevas novelas históricas. En efecto, como hemos deslizado al pasar, suele dejarse de lado la evidente disparidad ideológica entre muchos de los escritores a la hora de examinar la evolución del subgénero, lo cual ha derivado en flagrantes simplificaciones, ocultamientos, olvidos, etc. por parte de 
A la busca del colón perdido: modulaciones en torno...

la historia de la literatura que de ese modo, paradójicamente, comete los excesos que muchas de las novelas estudiadas (o dejadas de lado y, por lo tanto, silenciadas) pretenden subsanar.

\section{Descubrimiento y conquista como evento modernista}

Por ser, como queda dicho, un tema tan repetidamente abordado por parte de la crítica, no es nuestro objetivo realizar un abordaje teórico sobre las características de la nueva novela histórica. Para ello, remitimos al lector a los trabajos clásicos que hemos mencionado anteriormente y a otros que incluimos en la bibliografía. En cambio, nos parece de gran utilidad resaltar un tema en el cual se ha insistido proporcionalmente mucho menos que es el de las relaciones entre la nueva narrativa histórica y algunas concepciones historiográficas que podrían encuadrarse en el marco de la posmodernidad ${ }^{4}$, fundamentalmente en la línea demarcada por Hyden White. Efectivamente, análisis como los de White permiten postular un interés creciente por parte de los historiadores en cuanto a los planteamientos sostenido desde la ficción, al mismo tiempo que permiten introducir en la praxis literaria un enfoque de la concepción historiográfica que delimita un marco pertinente para encuadrar la producción artística desde una perspectiva más rigurosa que la utilizada por muchos de los críticos literarios. Resulta de esta concepción un círculo de retroalimentación entre la historiografía y la literatura, de tal modo que puede postularse un campo de colaboración entre ambas disciplinas para explorar los límites hipotéticos que las separan, pero también las zonas grises en donde ambas pueden coexistir y estimularse mutuamente.

Para avanzar sobre este asunto, hemos seleccionado un corpus de tres novelas que giran en torno a un mismo tema y que nos servirán de marco para estudiar el modo en que las relaciones entre ficción e historia se tensan cada vez más. Las obras en cuestión son: El arpay la sombra (1978) de Alejo Carpentier, Los perros del Paraíso (1983) de Abel Posse y El conquistador (2006) de Federico Andahazi. La inclusión de las dos primeras es justificable en función de su iconicidad en el contexto de la nueva novela histórica, mientras que la novela de Andahazi representa un interesante momento de desarrollo de

Anos 90, Porto Alegre, v. 21, n. 40, p. 425-462, dez. 2014 
la narrativa histórica y es, además, una obra que pocas veces ha sido analizada desde una perspectiva crítica.

El tema que abordan las tres novelas del corpus es el descubrimiento de América en 1492, asunto que como dijimos es de importancia capital en la nueva novela histórica. Todos los estudiosos del subgénero que hemos considerado anteriormente, a pesar de las notables diferencias que se perciben en sus enfoques, destacan la centralidad de este tema en la producción literaria de la época. Podríamos arriesgar la idea de que la combinación entre la posmodernidad (tanto en su aspecto ideológico sobre la imposibilidad de conocer con certeza la verdad como en su manifestación estética) y el efecto opresivo de los regímenes dictatoriales latinoamericanos con las crisis económicas mundiales por trasfondo sugirieron a los escritores la idea de que era necesario "redescubrir" y "reconquistar" el "descubrimiento" y la "conquista". Además de los elementos identitarios y fundacionales que pueda atribuírseles, el carácter textual que el descubrimiento y la conquista de América fueron adquiriendo con el tiempo ${ }^{5}$, fundan las condiciones excepcionales que lo convierten en un tema privilegiado para el abordaje literario.

En este sentido, una primera consideración que podemos hacer, y que va más allá del aniversario por el quinto centenario, es que parte de la preponderancia del asunto en la narrativa histórica contemporánea tiene que ver con su construcción historiográfica como un evento modernista. En efecto, en nuestra opinión la utilización de la efeméride del descubrimiento es una base para que los escritores configuren aquel evento, único en la historia de la humanidad, desde una perspectiva posmoderna al asignarle sentido a partir de sus experiencias contemporáneas. Los textos elegidos representan el drama americano casi exactamente en la línea en la que Hyden White define los eventos modernistas del siglo XX como eventos cuya escala, intensidad y alcance:

[...] los hacen impermeables a las categorías tradicionales de la representación y explicación histórica. Con esto quiero decir que lo que solemos denominar "conciencia histórica" no contiene ni las categorías ni las técnicas representacionales requeridas para la historización efectiva de estos hechos. Por 
A la busca del colón perdido: modulaciones en torno...

ejemplo, estos eventos no se prestan para el tipo de tratamiento "dramático" del que se sirvieron los historiadores por dos milenios como base para la representación de acontecimientos específicamente "históricos". Esto significa, entre otras cosas, que no se prestan a ser interpretados por medio de la narrativización ${ }^{6}$ (WHITE, 2010, p. 154).

Si bien White formula estas observaciones para acontecimientos característicos del siglo XX y para condiciones muy especiales que los favorecen (tales como los efectos a gran escala de la industrialización, la globalización de la información y el ocultamiento por exceso de sobredocumentación), podemos afirmar que en las ficciones estudiadas la representación de ciertos hechos (como la explotación humana y las masacres cometidas en el continente americano a manos de los europeos) son construidos por los novelistas en términos análogos a los que podrían utilizarse en representaciones fundantes de la idea de posmodernidad tales como el Holocausto e Hiroshima, pero también de otras tantas atrocidades recientes. Por lo tanto, si en una primera mirada es posible afirmar que hay una llamada de atención ética por parte de los novelistas sobre la especificidad histórica de la conquista del "Nuevo Mundo"; en un segundo momento también puede asegurarse que una construcción de este tipo lanza una profunda reflexión sobre la persistencia de esos efectos en el presente y sobre las condiciones sociales de la América contemporánea sumergida en la violencia y el subdesarrollo originados como consecuencia de la etapa avanzada del capitalismo en los países dominantes ${ }^{7}$.

A partir de esa base común en el corpus seleccionado, nuestra hipótesis de trabajo sugiere que el análisis de las tres novelas, producidas en diferentes estadíos del desarrollo de la nueva narrativa histórica y por escritores con profundas diferencias tanto en lo relativo a sus concepciones estéticas como a sus objetivos ideológicos, podría permitir revelar la creciente radicalización de algunas de las operaciones a las cuales el material histórico es sometido. Estas observaciones podrían representar un punto de reflexión sobre las continuidades y rupturas en la nueva novela histórica, como así también en lo que a la historiografía se refiere. En un sentido análogo, White, siguiendo a Marx, reflexiona:

Anos 90, Porto Alegre, v. 21, n. 40, p. 425-462, dez. 2014 
Visto desde esta perspectiva, el apotegma de Marx acerca de ciertas clases de eventos históricos ocurriendo "de alguna manera, dos veces, la primera vez como una tragedia, la segunda como una farsa", puede ser modificado para decir: cualquier secuencia de eventos puede ser alegorizada ya como tragedia ya como farsa sin amenazar la precisión con la cual los "hechos" son representados en el relato en efecto contado de una manera más que de la otra (WHITE, 2010, p .60, cursivas en el original).

En otras palabras, pensamos que esta mirada permitiría fijar algunas pautas de discusión en lo relativo tanto a las relaciones de la literatura con la historia como de las utilidades que la historia podría obtener de la literatura. Las especulaciones que buscamos realizar se centran en proponer la interferencia entre dos campos que muchas veces, desde la teoría, se imaginan como paralelos pero que desde la práctica se muestran predispuestos a la mixtura. Esta línea de trabajo se deriva también del conjunto de las reflexiones de Hyden White cuando apuntan a resaltar, por una parte, la arbitrariedad que aflora del hecho de tener por "natural" el modo que la historiografía ha consagrado para los estudios históricos y, por otra parte, la necesidad de que los historiadores recurran a la teoría literaria para comprender los mecanismos narrativos que han estandarizado para la escritura de sus textos.

\section{El rol de la crónica}

Según Fernando Aínsa, la novela histórica contemporánea debe pensarse como una continuación del género de la crónica:

[...] cuya original intención histórica es hoy ficcional; crónicas que, en definitiva, pueden llegar a ser representativas de la otra historia de América que está por escribirse: la de las minorías, vencidos y marginados, la del pensamiento heterodoxo disidente (AÍNSA, 2003, p. 33). 
A la busca del colón perdido: modulaciones en torno...

La "vocación literaria de las Crónicas", de acuerdo con el mismo autor, ha sido evidenciada en numerosos estudios en los que se resalta que son un subgénero "[...] donde tanto importa el documento y el archivo como la técnica narrativa utilizada" (2003, p. 34). Si bien en lo esencial estamos de acuerdo, en nuestra perspectiva el enfoque de Aínsa presenta algunos puntos de modo un tanto simplificado. Esta simplificación se aprecia especialmente en dos aspectos, siendo el primero el de la idea de que la crónica hoy tiene una intención ficcional, algo que resulta poco sostenible desde la práctica ya que, de hecho, desde hace algunas décadas asistimos a un resurgimiento de la crónica como medio de expresión válido frente a ciertas circunstancias y, consecuentemente, válido también como herramienta para investigar el pasado. El segundo punto es que la técnica narrativa es, como ha demostrado Hyden White, fundamental para casi todo el conjunto de la historiografía contemporánea.

En efecto, en algunos de sus textos Hyden White ha reflexionado sobre las formas canonizadas para contar la historia y ha establecido un sistema de relaciones que apuntan en una dirección similar a la que venimos desarrollando. El autor considera que la prevalencia de la narración frente a otras formas (consideradas imperfectas o, incluso, proto-históricas) es el producto de una imposición, de una decisión subjetiva que naturaliza una de las posibilidades en detrimento de las alternativas plausibles:

Si bien los anales representan la realidad histórica como si los acontecimientos reales no mostrasen la forma del relato, el autor de la crónica la representa como si los acontecimientos reales se mostrasen a la conciencia humana en la forma de relatos inacabados. Y el saber oficial quiere que, por objetivo que pueda ser un historiador en su presentación de los hechos, por juicioso que haya sido en su valoración de las pruebas, por escrupuloso que haya sido en su datación de las res gestae, su exposición seguirá siendo algo menos que una verdadera historia si no ha conseguido dar a la realidad una forma de relato (WHITE, 1992, p. 21).

Anos 90, Porto Alegre, v. 21, n. 40, p. 425-462, dez. 2014 
Entonces, parte de la actitud contestataria de la nueva novela histórica frente al discurso de la historia oficial podría no encontrarse necesariamente en los temas que se abordan o en el modo de encararlos, sino en las fuentes documentales a las cuales recurren los autores para informarse y, consecuentemente, en la categoría que se les asigna. De hecho, White explica que es posible considerar formas como los anales y las crónicas:

[...] no como las historias imperfectas que convencionalmente se consideran que son, sino más bien como productos particulares de posibles concepciones de la realidad histórica, concepciones que constituyen alternativas, más que anticipaciones fallidas del discurso histórico consumado que supuestamente encarna la historia moderna (WHITE, 1992, p. 21-2).

Desde este punto de vista, las tres novelas incluidas en nuestro corpus retoman esa concepción e intentan generar lecturas dislocadas a partir de la alternativa que representa la crónica como modo de conocimiento. En efecto, confrontando la base cronística con los relatos históricos tradicionales, los novelistas proponen una vuelta a la crónica no por considerarla más fiable que la historia oficial, sino por encontrar que es más fácil descubrir los ocultamientos y los silencios que se esconden en su seno. Incluso es factible postular que puede determinarse una graduación en estas relaciones, de modo que los límites se van ampliando a partir de operaciones de relectura y de análisis cada vez más extremas de aquellos textos que son utilizados como fuentes:

1. En El arpa y la sombra, la relación del texto literario con la crónica se encuadra dentro de una modulación que podríamos denominar como una advertencia sobre la credibilidad de la historiografía. En este sentido, recurriendo a los diarios de Colón (de los cuales Carpentier inserta literalmente algunos fragmentos en el cuerpo de su novela), el autor pretende

Anos 90, Porto Alegre, v. 21, n. 40, p. 425-462, dez. 2014 
A la busca del colón perdido: modulaciones en torno...

resaltar la realidad irrefutable que ellos transmiten, con sus luces y sombras, por sobre las manipulaciones con fines explícitamente doctrinales que pueden apreciarse en los textos bio-históricos escritos por Roselly de Lorgues o León Bloy. Esta modulación surge como una reacción activa y violenta del escritor frente a la evidente manipulación ideológica de las fuentes históricas por parte de la Iglesia católica, asunto explicitado por Carpentier tanto en diversos paratextos ${ }^{8}$ como, metaficcionalmente, desde la novela misma. Frente a la falsedad de los historiadores y biógrafos, Carpentier presenta a un Colón que se habla en primera persona a sí mismo y que, revisando los diarios, va destejiendo una red de ocultamientos y silencios deducibles del material escrito. En otras palabras, lo que surge de la novela de Carpentier es que los diarios y las cartas de Colón, a pesar de maquillar algunos hechos, son mucho más elocuentes y fidedignos que las historias aparecidas con posterioridad y se sugiere, también, que si no han revelado estos secretos antes es porque quienes los han leído, han interpretado voluntariamente sus sentidos en otras direcciones.

2. Una segunda modulación de las relaciones entre los textos literarios y la crónica, es la que establece Posse en Los perros del Paraíso y que podríamos llamar de amarga desilusión y circularidad. En efecto hay insertos en la novela una serie de elementos que, al igual que en el caso de El arpa y la sombra, provienen literalmente de las crónicas. Sin embargo una diferencia profunda radica en que Posse introduce estos fragmentos no tanto para contrastarlos con las historias, sino para postular un continuum que alcanza hasta nuestros días y que iguala la masacre perpetrada por los conquistadores con el terrorismo de estado de las décadas de 1970 y comienzos de la de 1980. La intertextualidad se torna así mucho más paródica que en Carpentier. Posse llega a mencionar en su novela famosos estudios académicos sobre las crónicas con el claro objetivo de desnudar la incertidumbre que se deriva por igual de los cronistas originales como de los historiadores contemporáneos: en este sentido debemos recordar que Tzvetan Todorov ha sido transformado en

Anos 90, Porto Alegre, v. 21, n. 40, p. 425-462, dez. 2014 
un personaje de la novela (el Lansquenete Todorov) y que participa de las acciones como uno de los integrantes de la comitiva de Colón. Finalmente, la intertextualidad propuesta por Posse llega un paso más allá al discutir, desde la ficción misma, la teoría deslizada por Carpentier en El arpa y la sombra en relación a los amoríos entre Colón y la reina Isabel.

3. En tercer lugar, podemos identificar en El conquistador un recurso aún más radical que los analizados hasta ahora y que lleva la narración hasta los límites del género histórico, dificultando incluso la tarea de considerarla como una novela del descubrimiento y de la conquista. Nos referimos a la operación de invertir completamente el relato clásico para imaginar a un hipotético Colón mexicano que "descubre" Europa justo antes de que el almirante genovés zarpe hacia occidente en $1492^{9}$. Esta modulación de las relaciones entre la ficción y el texto cronístico, que denominaremos contrafáctica, representa una opción que materializa de modo más extremo las premisas de la estética de lo carnavalesco en el sentido bajtiniano de la expresión. Si el anacronismo resultaba en cierta medida sorpresivo en el texto de Carpentier (incluso cuando participan fantasmas de la acción en la tercera parte) y devenía estructural en el de Posse (en tanto el tiempo allí es un continuum en el cual cuesta separar lo antiguo de lo contemporáneo), Andahazi propone una naturalización de la conjetura ${ }^{10}$ a partir de la cual repensar las relaciones entre Europa y la América del siglo XVI y del XXI. Aunque la base cronística no aparece tan literalmente explicitada como en los casos anteriores, es evidente que El conquistador entabla un diálogo con esos textos por medio de la alusión y de la lógica del "mundo al revés" bajtiniana. Para mencionar un ejemplo, podemos recordar que en la novela no es necesario defender la religiosidad de los indígenas ni justificar sus sacrificios humanos explícitamente, sino que al presentar el catolicismo español visto desde los ojos de los expedicionarios mexica, el Cristo crucificado y los Autos de Fe resultan más sanguinarios que los rituales practicados por sus sacerdotes

Anos 90, Porto Alegre, v. 21, n. 40, p. 425-462, dez. 2014 
A la busca del colón perdido: modulaciones en torno...

en Tenochtitlán. Esta desnaturalización del sentido común impuesto a todo occidente a partir de la dominación europea, resulta eficaz para cuestionar parte del paradójico discurso oficial que justificó el exterminio de los nativos americanos como una forma aceptable y hasta piadosa de acabar con su crueldad.

Aunque con profundas diferencias, estas tres modalizaciones comparten la base común de plantear la necesidad de revisar el relato histórico y, como un agregado secundario, de sugerir que esa revisión puede encararse merced a una lectura atenta y desmitificadora de los textos de los cronistas. Podría decirse que las tres novelas proponen un ejercicio de reposición de contextos, a través del cual reenvían al lector a realizar un autoexamen de su sentido común acerca de la historia. Desde esta perspectiva, podría argumentarse que las ficciones estudiadas son una verdadera mise en scène de algunas de las propuestas de Pierre Bourdieu, sobre todo cuando insiste en la necesidad de que los textos del pasado deben ser revisados (revisitados) teniendo en cuenta tanto el contexto de su creación como el de su reproducción y circulación, como así también el de los intereses que subyacen a cada etapa y a cada agente que participa del proceso. Principalmente puede destacarse que las novelas entablan, desde lo implícito de su práctica, la lucha contra lo que Bourdieu ha considerado como pensamiento sustancialista:

El modo de pensamiento sustancialista que es el del sentido común - y del racismo - y que conduce a tratar las actividades o las preferencias propias de determinados individuos o determinados grupos de una sociedad determinada en un momento determinado como propiedades sustanciales, inscritas de una vez y para siempre en una especie de esencia biológica o - lo que tampoco mejora - cultural (BOURDIEU, 1997, p. 15, cursivas en el original).

El traslado de esta visión sobre el material histórico supone un fuerte alegato en contra de la repetición de relatos naturalizados acerca del pasado que, a su vez, se canalizan a través de formas, también naturalizadas, de contar.

Anos 90, Porto Alegre, v. 21, n. 40, p. 425-462, dez. 2014 


\section{La desnaturalización del pasado: hacia una poética del extrañamiento histórico en El arpa y la sombra de Alejo Carpentier}

Por todo lo expuesto en el apartado anterior, se hace evidente que la desnaturalización del pasado histórico, a través de las diversas modulaciones que los escritores establecen con el documento que les sirve de base para sus ficciones, permite redibujar una serie de líneas que son verdaderas columnas vertebrales en la construcción, en este caso, de los eventos del descubrimiento y de la conquista de América.

Un examen de algunos elementos en la representación de la que es objeto Cristóbal Colón en las novelas elegidas nos permitirá observar de qué modo los relatos estandarizados son forzados hacia nuevos límites. Posteriormente también consideraremos el modo en que la intertextualidad colabora, desde otro lado, en la misma tarea.

En cierta medida, la selección del corpus analizado en este trabajo se justifica en los modos en que la figura del Almirante aparece en ellos. Podemos comenzar destacando que existe una serie de elementos concordantes en su tratamiento que apuntan, generalmente, a desmitificar la construcción de la que ha sido objeto. Esto se verifica, fundamentalmente, en El arpa y la sombra y en Los perros del paraíso donde Colón se desempeña como personaje principal. En ambas obras no solamente se lo presenta como amante de la reina Isabel, como hemos dicho antes, sino que también se insiste, por ejemplo, en su presunto origen judío. La configuración de un Colón hebreo influye en la desmitificación de la figura instaurada por la historiografía clásica y en la mención del drama de los criptojudíos. Por ejemplo, cuando el almirante necesita vestir a los indígenas llevados a Europa en el regreso del primer viaje y no sabe muy bien cómo hacerlo:

Me vino de providencia, en tal trance, un sastre judío a quien había conocido antaño junto a la Puerta de la Judería de Lisboa, donde tenía oficina y que ahora, pasado de circunciso a genovés - jcomo tantos otros! - se hallaba en la ciudad (CARPENTIER, 2004, p. 147, el resaltado es nuestro).

Anos 90, Porto Alegre, v. 21, n. 40, p. 425-462, dez. 2014 
A la busca del colón perdido: modulaciones en torno...

La aclaración que hemos resaltado en la cita precedente no es en absoluto inocente y apunta a insinuar la presencia de una minoría cuya historia particular, aunque ocultada de la memoria colectiva por diversas razones, merece la pena de ser evocada. La alusión al judaísmo también encuentra una canalización menos seria a través de alusiones de orden sexual que, por motivos evidentes, remiten a una dimensión carnavalesca, como cuando Colón visita a la zona roja y confiesa que “[...] las 'ginovesas' [...], venidas de alguna judería, me hacían un guiño cómplice al tentarme el rejo" (CARPENTIER, 2004, p. 63).

Si se atiende a las consideraciones de Carpentier, este ocultamiento no solamente respondería a la necesidad de evitar que se pensara que la corte de la Reconquista, de la expulsión de moros y de judíos y, por supuesto, de la Inquisición había favorecido la expedición ideada y comandada por un judío ${ }^{11}$ y que se beneficiaba económicamente de los mismos financistas que condenaba al exilio o a la muerte ${ }^{12}$. Por el contrario, al entender la Conquista de América como un acto teológico y, casi como una consecuencia directa, pretender que Colón fuera canonizado, la Iglesia precisaba esconder lo que de ese modo resultaba ser parte del origen espúreo de la empresa.

Otro de los aspectos que mejor ejemplifican nuestro punto de vista acerca de la desmitificación de la figura de Colón es el hecho de que se lo represente como un hombre intelectualmente muy limitado, poco dado a las deducciones lógicas y cuyo éxito en la empresa se debió principalmente a méritos y conocimientos recibidos (o directamente robados) de otros hombres más brillantes que él. En la segunda parte de El arpa y la sombra, se sugiere que las noticias que obtiene sobre la exploración llevada adelante por algunos de los pueblos nórdicos hacia el occidente son las que lo impulsan a presentar el proyecto a los reyes:

Pero si viene a saberse de mi certeza de que navegando hacia el Oeste iré a lo seguro por lo sabido en la Tierra del Hielo, quedaría muy menguado el mérito de mi empresa. Peor aún: no faltaría el familiar, el favorecido, el confidente, el brillante capitán de un soberano, que consiguiera las naves en mi lugar, y me 
birlara la gloria de Descubridor que tengo en mayor precio que cualquier otra honra. Mi ambición ha de aliarse al secreto. De ahí que deba callar la verdad (CARPENTIER, 2004, p. 84-85, resaltado nuestro).

El objetivo, muy transparente, es el de desmontar la figura de Colón en dos de los núcleos básicos del relato predominante, es decir, en el del espíritu aventurero que lo llevó a navegar hacia lo desconocido y en el carácter racionalista de sus deducciones, que lo enfrentaron con el aparato oscurantista proveniente del medioevo. Así, el Almirante que surge de las páginas de Carpentier es un hombre dubitativo, temeroso, oportunista y, por sobre todas las cosas, muy codicioso. Pero estos presupuestos no son suficientes para revelar, como el escritor cubano se propone, las mentiras sobre las cuales se monta la maquinaria que oculta el pasado para construir una versión funcional a los intereses de diferentes núcleos de poder. Es por ello que, más allá de presentar una imagen desmitificada de Colón, se imponía la necesidad de interpelar desde la ficción una serie de escritos que intentaron construir la imagen de un Santo que permitiera "[...] compactar la fe cristiana en el viejo y nuevo mundo, hallándose en ello un antídoto contra las venenosas ideas filosóficas que demasiados adeptos tenían en América" (CARPENTIER, 2004, p. 49). Un buen ejemplo de esto se aprecia en el siguiente párrafo, en el cual el Papa Pío IX de Carpentier reflexiona sobre su intento de canonizar a Colón a partir de los documentos que posee (y que él mismo había encargado):

Trece años antes había pedido al Conde Roselly de Lorgues, escritor católico francés, que escribiese una verídica historia de Cristóbal Colón, a la luz de los más modernos documentos e investigaciones hechas acerca de su vida. Y en esa historia la había leído y releído veinte veces — aparecía claramente que el Descubridor de América era merecedor, en todo, de un lugar entre los santos mayores. El Conde Roselly de Lorgues no podía haberse equivocado. Era un historiador acucioso, riguroso, ferviente, digno de todo crédito, para quien el gran marino habia vivido siempre con una invisible aureola sobre la cabeza. Era tiempo ya de hacerla visible ad majorem Dei gloriara (CARPENTIER, 2004, p. 53, resaltado nuestro). 
A la busca del colón perdido: modulaciones en torno...

Carpentier desnuda de este modo el asunto de los usos de la memoria, de la construcción de una realidad con fines muy específicos e interesados que no se corresponden con la idea del reflejo imparcial que se pretende dar. Claramente las contradicciones entre la rigurosidad del historiador y su militancia "ferviente" para demostrar que el navegante llevaba una "aureola" invisible revelan las inconsistencias del discurso.

La pionera novela de Alejo Carpentier introduce, como hemos asegurado más arriba, una duda permanente acerca de la capacidad de los hombres para conocer el pasado. La desmitificación de la figura heroica de Colón como así también la reflexión acerca de la creación y utilización intencionada de esa estampa, supone una grave advertencia sobre la actividad historiográfica misma al demarcar sus límites y advertir sobre la manipulación de la documentación con propósitos no siempre revelados.

\section{La desnaturalización del presente: hacia una poética del exceso en Los perros del paraíso de Abel Posse}

$\mathrm{Si}$, como dijimos anteriormente, muchos autores coinciden en señalar que Alejo Carpentier, a partir de novelas como El arpa y la sombra, es uno de los padres de la nueva novela histórica, no es menos cierto que dicha modalidad fue descripta y definida teniendo en cuenta a otros autores posteriores al cubano. Uno de ellos fue Abel Posse, como lo señalaba María Beatriz Aracil Barón en un estudio dedicado al escritor:

En su deseo de ofrecer la otra cara de la historia, la «nueva novela histórica latinoamericana» (como sería definida, entre otros, por Seymour Menton) se estaba acercando especialmente a períodos conflictivos del pasado americano para ofrecer nuevas versiones de los mismos. En este sentido, títulos como El arpa y la sombra, de Alejo Carpentier (1979), El mar de las lentejas, de Antonio Benítez Rojo (1979), Crónica del descubrimiento, de Alejandro Paternáin (1980), o Daimón, del propio Abel Posse (1978), habían marcado ya nuevas formas 
de acercamiento a un período fundacional de la historia americana que sólo conocíamos desde la voz de los vencedores: el del Descubrimiento y la Conquista del Nuevo Mundo. Los perros del Paraíso, como después lo haría El largo atardecer del caminante, contribuyó sin duda a conformar esta visión desmitificadora del hecho histórico de la Conquista, convirtiendo a su autor en uno de los ejemplos paradigmáticos de este nuevo tipo de escritura (ARACIL BARÓN, 2004, p. 46).

En esta cita queda en evidencia la conexión y la importancia que tienen los dos primeros textos seleccionados para constituir el corpus de nuestro análisis en el contexto general de la nueva novela histórica. En cierta medida Los perros del Paraíso podría enfocarse como una intensificación de los recursos utilizados por Carpentier en su novela.

Efectivamente, por una parte, al considerar el modo en que algunos de los aspectos que hemos observado en la novela de Carpentier son tratados en Los perros del Paraíso, se hace evidente que amabas obras responden a lineamientos similares. Por otra parte, sin embargo, las estrategias y los límites que cada autor establece para la trasmisión de las ideas resultan muy diferentes. Tanto los principios comunes como las divergencias que existen entre ellos, se hacen especialmente visibles en el tratamiento que recibe la figura de Colón. Si para el escritor cubano Colón era un oportunista bastante ambiguo en cuanto a la finalidad de su periplo, para el argentino es llanamente un místico alucinado y un ignorante, cuyos devaneos mentales dejan entrever que nunca pensó en descubrir que la tierra era redonda. En el momento de idear cómo convencería a los reyes sobre la necesidad de apoyar su expedición, se nos indica que el almirante tiene el siguiente plan:

Iría al grano: les explicaría algo que tendría sin duda grandes consecuencias geopolíticas (como entonces no se decía). Les explicaría de qué modo, y contrariamente a la creencia de tantos, la tierra es plana. Se puede navegar hasta el fin de la Mar Océana donde se alza el reborde de tierra final que como un cantero contiene las aguas (POSSE, 1983, p. 72, resaltado nuestro). 
A la busca del colón perdido: modulaciones en torno...

La inversión opera sobre el lugar común habitual, según el cual Colón convenció a los reyes de que la tierra era redonda y de que era posible llegar hasta oriente navegando hacia el poniente ${ }^{13}$. A ello se suma el anacronismo que supone la inclusión del término "geopolítico" y que contribuye a reforzar nuestra idea de que el descubrimiento y la conquista de América pueden abordarse, atendiendo a la construcción discursiva más reciente del tema, como eventos modernistas en función de su masividad y, principalmente, de las peculiaridades de su tratamiento literario. En efecto, las consecuencias "geopolíticas" de la empresa narrada son inmensas, sus consecuencias alcanzan el presente de la escritura, y confirman la riqueza en concebir a gran escala el asunto. Pero dejando de lado el ejemplo particular que hemos comentado, la utilización de anacronismos en Los perros del Paraíso es de gran trascendencia para comprender la naturaleza de una obra en la que, como hemos indicado anteriormente, se insiste una y otra vez en relacionar los hechos acaecidos durante el viaje de 1492 con todo lo acontecido en los quinientos años posteriores a ese momento liminar. En otras palabras el narrador pasa de una época a la otra sin solución de continuidad, lo cual sirve para poner de manifiesto el largo proceso de dominación como una linealidad ininterrumpida:

Las danzas, tan graciosas y sanamente eróticas, como el areito y el naual, se fueron degradando a rumbones y milongas de burdel (ya no interesaban los finos movimientos de las manos ni las sugestivas posiciones de los ojos, sólo apreciaban el torpe y continuo temblor de las nalgas desnudas) (POSSE, 1983 , p. 237, resaltado del autor).

Este fragmento condensa los modos en que, según Posse, la conquista europea no solamente sirvió para desprestigiar y desintegrar la cultura de los pueblos originarios, sino que al degradarla, el producto resultante, más que una manifestación artística surgida del mestizaje, es la expresión de la dominación violenta (y violadora) de los cuerpos conquistados ${ }^{14}$. La elección de las danzas no es azarosa, sino que contiene un guiño intertextual hacia las crónicas de los primeros conquistadores: Bartolomé de las Casas y Alvar Núñez

Anos 90, Porto Alegre, v. 21, n. 40, p. 425-462, dez. 2014 
Cabeza de Vaca, entre otros, insisten en describir esos bailes en términos adánicos y en resaltar críticamente los intereses libidinosos de los europeos frente a las costumbres elevadas de hospitalidad de los indígenas americanos. Por lo tanto, además de señalar la intertextualidad subyacente, es posible insistir en la idea de que la novela de Posse es una elaboración paródica de lo expresado en las crónicas ${ }^{15}$.

Dicho nivel de significación paródica se intensifica en la utilización de elementos lingüísticos cada vez más abiertamente concernientes al contexto de violencia política que azotaba al continente en la fecha de escritura de Los perros del Paraíso. Así, podemos encontrar alusiones a la terminología eufemística utilizada por la junta militar para enmascarar los asesinatos de opositores políticos. Por ejemplo, cuando "Durante una acción represiva Anaó fue hecha prisionera con vida" (POSSE, 1983, p. 238, resaltado nuestro) y, ante su negativa a ser poseída por otro hombre que no fuera su marido, es torturada y asesinada por "aperreamiento". Este episodio da lugar a una nueva y provocativa maniobra intertextual ya que uno de los testigos del brutal crimen es "El fraile Landa" quien "contempló los hechos con franciscana tolerancia [y los] anotó así en el capítulo XXXII de su Relación" (POSSE, 1983, p. 238). Después de esta afirmación, Posse introduce literalmente el fragmento extraído de la Relación de las cosas de Yucatán de Diego de Landa.

Lo interesante, más allá de que sea inevitable asociar el destino de la Anaó de Posse al de miles de mujeres secuestradas, violadas y asesinadas durante la dictadura argentina que comenzó en 1976, es que la intertextualidad va un paso más allá y deviene feroz parodia de la intelectualización de la matanza cuando el narrador señala que "el lansquenete Todorov, que presenció esta atrocidad, creyó enloquecer de impotencia” (POSSE, 1983, p. 238). Este comentario alude al hecho de que Tzvetan Todorov no solamente utiliza el fragmento de Landa como epígrafe para su libro La conquista de América: el problema del otro, sino que simbólicamente dedica la obra a "[...] a la memoria de una mujer maya devorada por los perros”.

Este movimiento intertextual abarca, además de textos académicos o de análisis histórico-textual como el de Todorov, a textos de carácter específicamente literario equiparando de ese 
A la busca del colón perdido: modulaciones en torno...

modo el estatus de la autoridad académica con la de los cronistas y la de los escritores de ficción. El ejemplo más sobresaliente es la parodia, bajo la apariencia de una discusión y hasta de una refutación, de la teoría de Alejo Carpentier acerca de los amores entre Isabel y Colón:

Ante ella, la Reina, su carne [la de Colón] se retrajo sin posibilidad de movimiento alguno. (Por eso yerra el gran Alejo Carpentier cuando supone una unión sexual, completa y libre, entre el navegante y la Soberana. La noble voluntad democratizadora lleva a Carpentier a ese excusable error. Pero es absolutamente irreal. La intimidación del plebeyo fue total en el aspecto físico. Total, en cambio, fue su descaro metafísico y así alcanzó la liberación del panorgasmo) (POSSE, 1983, p. 119-20).

El tono socarrón del narrador para referirse tanto a Todorov como a Carpentier y a los cronistas hace pensar que las alusiones no se orientan solamente hacia un ejercicio erudito del escritor, a través del cual se propone revelar sus conocimientos sobre el tema. Por el contrario, se trata de un intento por mostrar la costura oculta de la intervención textual: la derivación más palpable de estas consideraciones es que siempre hay una faceta diferente, una dimensión no revelada de la historia narrada que, al ser explicitada, desactualiza y hasta ridiculiza las teorías precedentes.

Otro aspecto a tener en cuenta para medir la distancia entre la obra de Carpentier y Los perros del Paraíso es, nuevamente, la insistencia en el supuesto judaísmo de Colón. Si en El arpa y la sombra ese aspecto escamoteado de las páginas de la historia oficial se sugería, al menos en parte, para desacreditar la versión de la Iglesia Católica; en la obra de Posse, en cambio, resulta un elemento fundamental para presentar su figura como la de un oportunista que no logrará nunca abandonar la ambigüedad con la que su cuerpo es marcado. El tratamiento del tema resulta también una muestra de cómo los recursos estéticos y temáticos van extremándose de una novela a la otra. Aunque ya la utilización del asunto por Carpentier incluía elementos asociables a lo carnavalesco, en cuanto a las connotaciones

Anos 90, Porto Alegre, v. 21, n. 40, p. 425-462, dez. 2014 
escatológicas y sexuales que podrían vincularse con la circuncisión, es Posse quien consigue darle mayor trascendencia y humorismo a las situaciones derivadas. Ya en la cronología que precede a la primera parte de la novela, puede leerse: "1468 - Tardía, ambigua e intencionada circuncisión de Cristóbal Colón” (p. 10). Cuando el joven Cristóbal es llevado por Domenico (su padre) ante un rabino, el narrador explica la naturaleza de la intervención:

Domenico había pactado con el rabino una circuncisión práctica, con el fin de que el muchacho pudiese pretender sin desventaja un puesto en alguna multinacional. Ibn-Solomon sugirió su especialidad: un corte medio para ambos propósitos. Una circuncisión de uso pluriconfesional que aunque no fuese muy homologable en sinagoga, resultase aceptable para banqueros, armadores, prestamistas. Y que no expusiera al joven al creciente rencor antisionista de los imperios nacientes. (Era un tiempo de mutación. Desde los cuatro extremos del mundo civilizado llegaban noticias de hebreos ardidos o lapidados con entusiasmo) (POSSE, 1983, p. 40).

El éxito de Colón para moverse en las estructuras del poder dependerá en el futuro de esta pequeña cirugía que, según el rabino que la ejecutó, le permitiría “[...] ser un elegido los sábados, goim los domingos" (POSSE, 1983, p. 41). Este comentario, como así también el espíritu en general de la cita anterior, pone de relieve la dinámica de lo carnavalesco literario, cuya naturaleza dilucidara magistralmente Mijail Bajtín en su estudio sobre la poética de Dostoievsky:

Todas las imágenes del carnaval son dobles, reúnen en sí ambos polos del cambio y de la crisis: nacimiento y muerte [...], bendición y maldición [...], elogio e injuria, juventud y vejez, alto y bajo, cara y trasero, estupidez y sabiduría. Para el pensamiento carnavalesco son muy características las imágenes pares contrastantes (alto-bajo, gordo-flaco, etc.) y similares (dobles-gemelos). También es típica la utilización de los objetos al revés (BAJTín, 1986, p. 177). 
A la busca del colón perdido: modulaciones en torno...

Esta acción carnavalesca emprendida por Abel Posse se asienta sobre el espíritu paródico, que busca marcar las relaciones de distancia entre el texto o la imagen original y el nuevo comentario. Es en función de ello que Colón es y no es judío, es y no es un genio visionario, es y no es amante de la Reina. El descubrimiento de América es, en realidad, el descubrimiento de Europa por parte de los indígenas americanos. La conquista es, en esencia, un signo que contiene la violencia política que ahogó al continente durante los siguientes quinientos años. Ese sentido del carnaval es el que permite insistir en la idea de que la historia, como la vida humana, es un campo sembrado de matices y no de seguridades, de ambigüedades que necesitan de la mirada de un individuo para superar el caos informe en que se presentan y adquirir una forma funcional a las instituciones. En otras palabras, para utilizar la terminología de Hyden White, los hechos necesitan ser narrativizados para convertirse en eventos históricos y a su vez, lo que puede deducirse de las novelas estudiadas hasta aquí es que la formulación a la que han sido sometidos los hechos del descubrimiento y la conquista constituyen un caso ejemplar de la naturaleza interesada (y no objetiva) del proceso de narrativización.

La profunda desilusión que se deriva de todo este conjunto de consideraciones sobre El arpa y la sombra y Los perros del Paraíso representa mucho más que la voluntad de “[...] disolución de la conciencia histórica sin la cual el hombre queda arrojado a un vacío que repugna a su naturaleza de ser en el tiempo" (SARMIENTO, 1989 , p. 236) y, también, representa mucho más que la intención de democratizar la historia que los críticos más entusiastas encuentran en el surgimiento y desarrollo de la nueva novela histórica. Es el tanteo de los límites y la comprobación, desesperante por momentos, de que las certezas que los historiadores han intentado inculcar son versiones inciertas e intencionadas de una realidad mosaica que siempre admite nuevas lecturas o, lo que es igual, que solamente por medio de la ilusión narrativa adquiere una apretada lógica que no tiene en la experiencia fáctica. 


\section{La desnaturalización de la memoria: hacia una versión contrafáctica de la historia en El conquistador de Federico Andahazi}

En comparación con las dos novelas analizadas anteriormente, El conquistador es una obra que no ha recibido prácticamente ninguna atención de parte de la crítica académica. Esto podría deberse a diversos motivos que abarcan, por ejemplo, cuestiones relativas a los esquemas de comprensión utilizados en el campo intelectual, las estrategias de posicionamiento establecidas por los escritores, la influencia de factores coyunturales de distinto tipo, entre otros, asuntos de los cuales no podremos ocuparnos aquí.

Desde nuestra perspectiva, en cambio, hay que decir que la novela de Federico Andahazi explora una línea iniciada por Abel Posse en Los perros del Paraíso cuando se mencionan hipotéticos encuentros entre las culturas incaica y azteca y las negociaciones emprendidas para invadir "las tierras frías del Oriente", es decir, Europa. La improbabilidad de estas negociaciones es esquivada con un hábil recurso de verosimilitud que se inserta en una verdad histórica repetidamente denunciada por muchos historiadores: la destrucción de los documentos producidos por las culturas autóctonas a manos de los europeos. El narrador comenta explícitamente que los encuentros habrían sido testimoniados en lo que fue denominado "Codex Vaticanus C, tercera parte", e inmediatamente aclara que no quedan vestigios de ellas porque el mencionado asiento se perdió para siempre "en la quemazón de documentos aztecas ordenada por el atroz obispo Zumárraga" (POSSE, 1983, p. 35).

En la novela de Posse ambas culturas inician negociaciones que fracasan por las profundas diferencias idiosincráticas entre ellas. Aparece nuevamente allí el anacronismo cuando, por ejemplo, el enviado Inca expresa una idea socialista de organización de la sociedad mientras que los aztecas tienen una organización orientada hacia el capitalismo: 
A la busca del colón perdido: modulaciones en torno...

Estos aztecas tenían aperturas a la gracia, a la inexactitud. Toleraban el comercio libre y la lírica. El Incario, en cambio, era geométrico, estadístico, racional, bidimensional, simétrico. Socialista, en suma (POSSE, 1983, p. 33).

Huamán Collo, el representante del incanato, y el dignatario azteca exteriorizan también cosmovisiones diferentes en cuanto al sentido que tendría la invasión de Europa. De hecho, algunos pasajes de la conversación entre ambos dejan traslucir la idea de que, si la historia hubiera sido al revés y los americanos hubieran conquistado Europa, se hubieran cometido excesos y atrocidades en nombre de sus dioses y de sus economías similares a las acontecidas en América:

- ¿Vale la pena invadir las tierras de los pálidos? - preguntó Huamán, escéptico, al tecubtli de Tlatelolco.

- Se pueden conquistar esas tierras, dominarlas - dijo el tecubtli como si no lo hubiese escuchado.

Huamán ya sabía que querían veinte o treinta mil de aquellos brutos pálidos para inaugurar, en el año azteca 219, el templo de Huitzilipochtli y conjurar el drama de la anemia solar [...]. Huamán Collo no podía abandonar la racional desconfianza de su señor, Túpac Yupanqui. Se suponía que los comerciantes de Tenochtitlán querrían abrigar a los pálidos con pieles de jaguar y de oso, estolas de plumas. Acostumbrarlos al tabaco y a la coca, alegrarlos con piedras de jade y cacao (POSSE, 1983, p. 33-34).

En este caso, el recurso de la conjetura se basa, obviamente, en el hecho de que la naturaleza del ser humano es la misma, provenga del rincón del mundo del cual provenga. Semejante concepción, si bien surgida de un profundo escepticismo existencial, tiene el objetivo de no idealizar inocentemente al grupo que finalmente llevó la peor parte porque fue dominado y exterminado sin ningún tipo de contemplación en el nombre y en los altares de una religión impuesta y, sobre todo, en los engranajes de un sistema económico cuyos beneficios y beneficiarios siempre estaban en Europa ${ }^{16}$. 
Esta línea narrativa conjetural, que en el total de la novela de Posse resulta algo marginal, es la base sobre la cual Andahazi construye El conquistador. Quetza, el protagonista de la novela, es algo más que un Colón azteca ${ }^{17}$ que deberá enfrentarse al oscurantismo de la religión y a las acusaciones de herejía para demostrar que la tierra es redonda. Es además un avezado ingeniero hidráulico y naval, un guerrero temible y un experto en astrología, lo que en alguna medida lo emparenta con el espíritu renacentista europeo, una especie de Leonardo Da Vinci americano.

En un poético pasaje de la novela, en el cual Quetza se encuentra en la cima de una pirámide con Ixaya, su amada, el muchacho revela su hipótesis sobre las esferas celestes:

Entonces Quetza, echado boca arriba, le decía a Ixaya que la Tierra no podía ser muy diferente de los mundos que se veían en aquel cielo nocturno. Que así como resultaba claro a simple vista que había otros mundos desperdigados por el cielo, era seguro que existían otras tierras dispersas en el mar, que si no se llegaban a divisar, como las estrellas, era porque la Tierra era esférica. Quetza estaba convencido de que si alguien se aventuraba mar adentro, después de algunos días de navegación, se toparía con otro mundo (ANDAHAZI, 2006, p. 46-47).

La aparición de una mente capaz de esas deducciones lógicas se presenta como una hipótesis absolutamente plausible, en función de los vestigios que sobrevivieron a la colonización europea. Lo más interesante, sin embargo, es cómo a partir de esta conjetura que cambia el sentido del movimiento "civilizatorio", usualmente concebido únicamente como una irradiación europea hacia América (y otras zonas del mundo), se deducen una serie de consecuencias desestructurantes que coinciden con la inversión carnavalesca que plantea Bajtín en su libro. Por ejemplo, el hecho de que las hipótesis de Colón pudieran haber estado fundamentadas en las versiones surgidas de los navegantes de los pueblos nórdicos tal y como lo recuerdan Carpentier y Posse en sus respectivas novelas es, en El conquistador, vista desde la perspectiva de Quetza: 
A la busca del colón perdido: modulaciones en torno...

Ignoraba si había otros pueblos en las demás tierras al otro lado del mar pero existían relatos que así lo señalaban. No sabía cuánto había de cierto en los cuentos que hablaban de los hombres barbados de cara roja que solían verse a veces cerca de las costas a bordo de barcos de innumerables remos, pero eran todos muy coincidentes (ANDAHAZI, 2006, p. 47).

Esta operación de extrañamiento, que permite abordar versiones conocidas desde una nueva perspectiva (porque, efectivamente, se especula con que los vikingos, por ejemplo, habían navegado hacia el oeste y entrado en las tierras americanas, pero poco se dice de la impresión que los habitantes autóctonos habrán sacado de aquellos encuentros), resulta especialmente elocuente cuando se supera la conjetura de la existencia de un Colón mexica, que podría quedar en lo anecdótico y hasta superficial, para develar una mirada del revés de la cultura europea. Esto se aprecia, fundamentalmente, en la segunda parte de la novela, titulada Diario de viaje de Quetra, que lleva además por subtítulo el de Cartas a Ixaya, y también en la tercera, que no tiene título alguno. En ambas secciones, la intertextualidad paródica con los textos de Colón alcanza su máxima expresión. Por ejemplo, cuando se apresta a iniciar su viaje detalla sus ilusiones en una carta a su amada:

Tengo la certeza, como tantas veces te he dicho, de que hacia el Levante existe otro mundo. Muchos honores me serán dados, así me lo ha dicho el rey, si hallo en mi empresa las tierras de Aztlan u otras donde extender los dominios del Imperio. Se me ha prometido, también, que sería nombrado príncipe de todas las islas y tierras que yo descubriese y ganase de aquí en adelante (ANDAHAZI, 2006, p. 127)

El título de Almirante de la Mar Océana creado por los Reyes Católicos en las capitulaciones de Santa Fe para Colón, resuena inevitablemente en las promesas del rey azteca para Quetza. El fin deslucido de ambos navegantes también será similar, lo cual revela que el poder se vale de ellos como instrumentos que son descartados cuando se convierten en un obstáculo para los intereses del imperio.

Anos 90, Porto Alegre, v. 21, n. 40, p. 425-462, dez. 2014 
Otro contrapunto interesante entre el diario de Colón y el de Quetza es el encuentro con los nativos europeos. Después de un viaje más largo de lo previsto y de un principio de sublevación de la tropa que lleva consigo, finalmente la expedición comandada por Quetza logra desembarcar cerca de Huelva. Apenas llegados, los americanos se topan con campesinos que observan aterrados sus trajes de guerra, la ferocidad con la cual carnean a una oveja para saciar el hambre que casi los había llevado a la muerte y que huyen despavoridos cuando el comandante de la avanzada mexica toma posesión de aquellas tierras en nombre de su rey (ANDAHAZI, 2006, p. 162). Quetza consignará en su diario aquel encuentro entre las culturas:

Los nativos de estas tierras son gentes muy cobardes que escapan ante nuestra sola presencia. Nunca pensé que podríamos entrar sin encontrar resistencia alguna. Tan temerosos son, que aún no me imagino cómo establecer contacto con ellos. No bien nos ven, huyen como liebres (ANDAHAZI, 2006, p. 163).

A partir de esto, un editor-narrador no identificado, que ha logrado conseguir los fragmentos del diario de Quetza que el lector tiene ante sus ojos, aclara que "con ese nombre bautizó Quetza aquellas primeras tierras habitadas por gentes blancas y asustadizas: Tochtlan, que significaba «el lugar de los conejos»" (ANDAHAZI, 2006, p. 163). La evidente alusión a la etimología fenicia que se atribuye al nombre Hispania, es decir, "tierra de conejos", es introducida como un guiño cómplice puesto que el significado es el verdadero, pero no el motivo de tal denominación. Este tipo de referencias que, insistimos, persiguen el propósito de presentar un mundo conocido bajo leyes desconocidas o invertidas, alcanza uno de sus clímax cuando los conquistadores se enfrentan con la religión de los nativos europeos. A su arribo al continente, los navegantes aprecian unas columnas de humo cuyo origen podrán explicarse poco después:

Cuando consiguió acercarse un poco más a la fogata, pudo comprobar lo que ya sospechaba. El olor de la carne asada 
A la busca del colón perdido: modulaciones en torno...

provenía del cuerpo calcinado de una persona que, atada a un palo, había sido inmolada. La multitud, al unísono, vociferaba una y otra vez: «iViva Cristo Rey!». Junto a la hoguera, Quetza distinguió un grupo de hombres vestidos de púrpura en cuyos pechos reposaba, otra vez, una cruz. Dedujo que eran los sacerdotes (ANDAHAZI, 2006, p. 166).

El espectáculo del suplicio público al que asisten los exploradores es descripto en términos similares a los que utilizaron los europeos al enfrentarse con las culturas americanas, pero con una diferencia: revela la hipocresía de quienes justificaron la necesidad de dominar a las etnias americanas utilizando como uno de los argumentos más fuertes el de la crueldad que representaban los sacrificios humanos. En la perspectiva desnaturalizada desde la cual se observa al cristianismo, las prácticas "naturales" de esa religión no están tan lejos de los sacrificios humanos ofrecidos por los sacerdotes aztecas. Para dar más fuerza al pasaje, el editor-narrador transcribe literalmente un fragmento del diario de Quetza:

Igual que en Tenochtitlan, aunque mucho más pequeño, hay aquí un centro ceremonial junto al teocalli. En este lugar de ceremonias se reúnen los nativos para asistir a los sacrificios humanos. La manera de ofrendar hombres a su Dios es clavándolos en una cruz, según atestiguan varias estatuillas, o bien quemándolos con leños verdes para prolongar la agonía, tal como yo mismo he podido ver. El Dios al cual hacen la ofrenda se llama Cristo Rey. Los nativos gritan su nombre mientras los sacerdotes hacen el sacrificio, del mismo modo que en Tenochtitlan el pueblo invoca el nombre de Huitzilopotchtli (ANDAHAZI, 2006, p. 166, resaltado nuestro).

En el fragmento citado se aprecia un estilo que remite directamente a las prácticas discursivas de los cronistas de indias, fundamentalmente, en sus intentos de traducir lo que veían en el nuevo mundo a conceptos comprensibles para el público al cual se dirigían. Análoga a la de las crónicas es también la fórmula lingüística para aumentar la verosimilitud del relato insistiendo en la autoridad del 
individuo que atestigua, en primera persona y a partir de su experiencia, acerca de acontecimientos que podrían parecer inverosímiles.

Aunque podría parecer que la novela de Andahazi es la menos intertextual de las analizadas en este trabajo, puede asegurarse que la intertextualidad en ella radica en una presencia muda de las fuentes cronísticas e históricas a partir de las cuales se ha elaborado un relato que, como dijéramos anteriormente, busca bucear en el revés de la trama a partir de una propuesta contrafáctica. Tal posición podría resumirse como una escritura invertida, especular, de los textos conservados. La cantidad de ejemplos de esta práctica en El conquistador excede los límites de este trabajo, aunque confiamos en que los señalados hasta aquí alcanzan para dar una idea de cómo la nueva novela histórica ha ido radicalizando cada vez más sus prácticas narrativas que son, al mismo tiempo, formas de reflexionar sobre el hecho histórico.

\section{Colonización y descolonización de Colón: algunas conclusiones}

A diferencia de las novelas de Carpentier y de Posse, la aparición del verdadero Colón en El conquistador es muy efímera. Se trata de una escena bastante breve en la que Quetza y el "almirante de la reina" quedan frente a frente $y$, a pesar de que ninguno de los dos revela abiertamente sus conocimientos, ambos parecen acceder a la certeza de que comparten el mismo secreto:

Se miraron a los ojos y, entonces, en ese destello, en ese silencioso choque de espíritus, supieron que ambos eran dueños del mismo secreto: la Tierra no era plana, sino esférica. Pero no pronunciaron una sola palabra. El navegante de la reina plegó sus mapas, hizo una reverencia al ilustre visitante y dio por concluida la reunión. Quetza pidió que le repitieran el nombre de aquel hombre inquietante.

- Colombo, Cristophoro Colombo - susurró a su oído uno de los edecanes de la reina (ANDAHAZI, 2006, p. 220-221). 
A la busca del colón perdido: modulaciones en torno...

El movimiento parabólico de la nueva novela histórica parece cerrarse muy cerca de donde comenzó, de modo que ya no es necesario presentar a Colón ni como amante de la reina, ni como judío, ni como un tonto con suerte para advertir sobre los riesgos de creer ciegamente en el relato historiográfico. Sencillamente, a los ojos de Quetza Colón es un hombre sumamente peligroso que podría liderar hasta las costas de su patria a una enorme flota invasora. Tratará de advertir sobre este peligro a su rey cuando regrese a Tenochtitlán, pero no será oído y pasará sus días exiliado y contemplando el mar, esperando el momento “[...] en que, desde el horizonte, surgieran los mástiles de las naves del almirante de la reina, trayendo consigo los dioses de la muerte y la destrucción" (ANDAHAZI, 2006, p. 282).

A esta altura parece necesario aclarar que no se trata de decidir entre alternativas que proponen que la nueva novela histórica puede reemplazar a la historiografía o si no debe ser considerada de otro modo que como un divertimento. Resulta evidente que ninguna de las opciones dará una respuesta acertada, de hecho quizás no exista una respuesta.

Es evidente que la historiografía basa su especificidad en una serie de estándares que la novela histórica contemporánea ni quiere ni necesita respetar, pero es también evidente que esos estándares no alcanzan para representar la realidad que es caótica, múltiple, infinita. En este sentido, el aporte de la nueva novela histórica reside en la capacidad de sugerir, de admitir hipótesis que, aunque no siempre demostrables, constituyen un factor de desnaturalización de lo artificialmente, ideológicamente y metodológicamente naturalizado. No necesariamente era el objetivo específico de ninguno de los novelistas aquí considerados que el lector creyera que Cristóbal Colón era un ignorante o un ladrón de ideas, pero sin dudarlo los tres escritores se proponían que se revisara el modo en que su figura y los hechos relacionados con su acción han sido homologados por los historiadores y retransmitidos por las instituciones educativas.

La posibilidad de pensar la re-construcción (o la demolición) del descubrimiento de América y de la conquista tal como la emprenden

Anos 90, Porto Alegre, v. 21, n. 40, p. 425-462, dez. 2014 
los escritores de la nueva narrativa histórica que hemos analizados, confiriéndole el estatus de un evento modernista, ubica a esta producción en conjunto como una forma literaria de vivificar el conocimiento en torno a un hecho que no puede representarse a través de los canales tradicionales de la expresión histórica, como hemos visto de acuerdo a la teoría de Hyden White. Herramientas que no son exclusivas de la posmodernidad, pero de las cuales se valen los escritores posmodernos para transmitir sus perspectivas, confluyen y configuran los materiales representacionales característicos de esa operación vivificante: la parodia como un modo de reinterpretación crítica, el carnaval bajtiniano como medio para desacralizar la solemnidad de las versiones canonizadas, la conjetura para sugerir que otras hipótesis son posibles. Estos y otros recursos han sido adoptados como banderas por los autores contemporáneos con el afán de hacer extraño lo que antes era natural o, para utilizar la terminología bourdeseana, para cuestionar el sentido común de los lectores. En este sentido, si bien nuestras consideraciones se basan en un corpus bastante pequeño de novelas, unido temáticamente, las conclusiones son aplicables a un conjunto mucho mayor de textos producidos durante las últimas décadas.

\section{IN SEARCH OF LOST COLUMBUS: MODULATIONS AROUND THE FIGURE OF ADMIRAL IN THREE NEW LATIN AMERICAN HISTORICAL NOVELS}

Abstract: In this paper we analyze some of the ways in which the new historical novel relates to the conqueror's chronicles and historical documents. We take as a point of reference one of the central themes of this literary phenomenon, the discovery and conquest of America, and focus on how the figure of Christopher Columbus is approached by three contemporary novelists in their productions: Alejo Carpentier's El arpa y la sombra, Abel Posse's Los perros del Paraiso and El conquistador by Federico Andahazi. Respecting a chronological order, we propose to reflect on the different modulations that the origianl materials have been treated by selected fiction writers, to better understand what are the ways in which 'history' and 'literature' are mixed and crosslinked.

Keywords: New historical novel. Fiction. Cronicle. Cristopher Columbus.

Anos 90, Porto Alegre, v. 21, n. 40, p. 425-462, dez. 2014 


\section{Notas}

${ }^{1} \mathrm{Al}$ respecto, Menton subraya que "no es por casualidad que el protagonista de la NNH paradigmática de 1979, El arpa y la sombra, sea Cristóbal Colón" (MENTON, 1993, p. 48). Según Menton, los debates en torno a esa fecha han sido un poderoso aliciente para la inspiración artística, cuyas manifestaciones traspasan el núcleo de la nueva novela histórica en particular y de la literatura en general, para evidenciarse en otros ámbitos culturales muy disímiles como el de la filatelia y la arquitectura, por ejemplo. Juan José Barrientos defiende un punto de vista diferente en su trabajo Reynaldo Arenas, Alejo Carpentier y la nueva novela histórica hispanoamericana.

${ }^{2} \mathrm{Al}$ respecto puede consultarse también el libro de Menton (p. 51) y el artículo de Pons (p. 103), ambos ya citados.

${ }^{3}$ Una prueba de esto, es el párrafo final de un documento de las recensiones del Opus Dei (hecho público en un sitio web) donde se analiza El arpay la sombra de Alejo Carpentier, novela sobre la cual nos detendremos más adelante. El párrafo en cuestión dice así: "En suma, El arpa y la sombra es un intento de desmitificar el hecho del Descubrimiento y la labor evangelizadora de los misioneros españoles (p.e., p. 48), a la vez que se señala que la Iglesia es un elemento retardatario del progreso, de la aventura cósmica que se inicia con la arribada de Colón a las costas salvadoreñas. Lo viejo, lo caduco, es Europa; lo nuevo, la esperanza, son los hombres de América, que con sus ideas y su esfuerzo serán capaces de llegar hasta las estrellas. En efecto, como dijo el propio Carpentier a propósito de este libro, en modo alguno cuenta aquí 'el poeta (o digamos: el novelista)' las cosas como sucedieron”. Disponible en: < http://www.opuslibros.org/Index_libros/ Recensiones_1/carpenti_arp.htm>. Consultado en: 25 ago. 2013.

${ }^{4}$ Introducimos el término posmodernidad, no sin tener conciencia de los problemas que conlleva su utilización en el contexto latinoamericano. A pesar de todas las objeciones que puedan interponerse, algunos recursos estéticos asociados a la posmodernidad, como la parodia, el carnaval bajtiniano, la conjetura, la intertextualidad, entre otros muchos, resultan indispensables para comprender las producciones estéticas contemporáneas. Asimismo, desarrollos teóricos, emprendidos muchos de ellos con propósitos e ideologías tan distintos, como podrían ser los de Fredric Jameson, Linda Hutcheon, Sandra Jara o Hyden White, han demostrado su utilidad explicativa incluso en la realidad hispanoamericana, para la cual no fueron originalmente pensados.

${ }^{5}$ Sobre este asunto, remitimos al lector al estudio ineludible de Todorov: $\mathrm{La}$ conquista de América: el problema del otro.

${ }^{6}$ Verónica Tozzi explica que la diferencia entre el concepto de narrar y el de narrativizar es: "la diferencia entre ofrecer un relato del pasado admitiendo que es

Anos 90, Porto Alegre, v. 21, n. 40, p. 425-462, dez. 2014 


\section{Diego Eduardo Niemetz}

uno el que narra, el creador del relato o narrador, y ofrecer un relato del pasado pretendiendo que uno encuentra el relato en los hechos mismos. Para White, este enmascaramiento del lugar del narrador tras el de descubridor sólo puede obedecer a alguna motivación política" (Ficción histórica, historia ficcional y realidad histórica, "Introducción", 15).

${ }^{7}$ La definición de posmodernidad como una etapa avanzada del capitalismo es esbozada por Fredric Jameson en El posmodernismo o la lógica cultural del capitalismo avanzado.

${ }^{8}$ En la solapa de la edición utilizada en este trabajo se lee esta declaración del autor: "En 1937, al realizar una adaptación radiofónica de El libro de Cristóbal Colón de Claudel para la emisora Radio Luxemburgo, me sentí irritado por el empeño hagiográfico de un texto que atribuía sobrehumanas virtudes al Descubridor de América. Más tarde me topé con un increíble libro de Léon Bloy, donde el gran escritor católico solicitaba nada menos que la canonización de quien comparaba, llanamente, con Moisés y San Pedro".

${ }^{9}$ El grupo humorístico Les Luthiers utilizó un recurso similar en 1977 para su pieza titulada "Cantata del Adelantado Don Rodrigo Díaz de Carreras, de sus Hazañas en Tierras de Indias, de los Singulares Acontecimientos en que se vio Envuelto, y de Cómo se Desenvolvió", en la que su protagonista descubría América un año antes que Colón y emprendía un viaje similar al de Alvar Núñez Cabeza de Vaca a través de todo el continente, desde el futuro Río de la Plata hasta Cuba. ${ }^{10}$ Tomamos el concepto de "conjetura" de Di Gerónimo, quien lo define como "una hipótesis interpretativa sobre hechos, basada en indicios o datos que un lector medio culto debe sospechar. En la conjetura se verifica el carácter de reescritura de otro texto al que remite. Desde el palimpsesto genettiano, la relación de transtextualidad que se instaura es la de hipo/hipertextualidad".

11 "Fuera de ese día, cuando muy rara vez me acuerdo de que soy cristiano, invoco a Dios y a Nuestro Señor de un modo que revela el verdadero fondo de una mente más nutrida del Antiguo Testamento que de los Evangelios, más próxima de las iras y perdones del Señor de las Batallas que de las parábolas samaritanas, en un viaje donde, para confesar la verdad, ni Mateo, ni Marcos, ni Lucas, ni Juan, estuvieron con nosotros (140).

12 “- Tienes el millón de maravedís" — me dijo [la Reina Isabel]. Lo había pedido al banquero Santángel con el autoritario apremio que yo bien le conocía. Le había dado, en garantía, unas joyas que, a la verdad, valían muchísimo menos — "Las recuperare cuando me plazca" — dijo "Y sin devolver el millón”. Me miró intencionalmente. "Hemos expulsado a los judíos. Bien vale un millón para Santángel, la ventura de poder permanecer en estos reinos donde tiene tan buenos negocios. Y ahora: ja enfardelar lo tuyo! Buena suerte. Y consigue todo el oro que puedas para que con él, podamos llevar la guerra al África” (CARPENTIER, 2004, p. 105-106). 
${ }^{13}$ Más adelante, insiste: “'Sólo con el coraje del que navega sabiendo que la tierra es plana - aunque el mundo sea redondo - se podría avanzar hacia las Indias! ¡Los Reyes deberían saberlo! [...]. Sentía la frustración del científico ante la impenetrabilidad de la ignorancia" (73). Es interesante comparar esta concepción de la figura de Colón elaborada por los novelistas hispanoamericanos con la plasmada por Ridley Scott en 1492: La conquista del paraíso (1992). La diferencia se aprecia ya en la escena inicial, cuando Colón se encuentra con su pequeño hijo en la costa observando un barco que se aleja lentamente. El almirante le explica al pequeño que la desaparición gradual del bajel en el horizonte ocurre por la curvatura del globo terráqueo, al cual compara con una naranja que ha estado sosteniendo entre sus manos mientras se desarrollaba el experimento. En general, y a pesar de presentar algunas insinuaciones relacionadas con, por ejemplo, los amoríos entre Colón e Isabel, el film de Ridley Scott apuntala la imagen canónica del almirante. Es necesario destacar también que el film insiste en presentar a un Cristóbal Colón que se rebela ante el oscurantismo de la España medieval (representado por los dominicos que pretenden impedir el viaje y que aparecen retratados como una amenaza por las constantes acusaciones de brujería que hacen pesar sobre todos aquellos que traen ideas nuevas o que contradicen en algún punto el dogma).

${ }^{14} \mathrm{Al}$ respecto ver el apartado "La doble censura: Colonia, Indios" en Historia e imaginación literaria: las posibilidades de un género de Noé Jitrik.

${ }^{15} \mathrm{En} A$ theory of parody: the teachings of twentieth-century art forms, Linda Hutcheon señala que la parodia posmoderna es: "repetition with critical distance, which marks difference rather than similarity” (6) y también, para ser más específicos en relación con el caso que nos compete, que "is not a matter of nostalgic imitation of past models; it is a stylistic confrontation, a modern recoding which establishes difference at the heart of similarity" (8).

${ }^{16}$ En este sentido, para indagar en la dimensión económica de la dominación europea a lo largo de los quinientos años, Las venas abiertas de América Latina de Eduardo Galeano sigue siendo una obra de referencia insoslayable.

${ }^{17}$ Es destacable el hecho de que Quetza no sea un azteca "puro", sino un huérfano, hijo de prisioneros acohuas y adoptado por un consejero mexica. Además de que es posible amalgamar la idea de un extranjero trabajando para el imperio con la del genovés Colón trabajando para la corte española, es interesante la deconstrucción del paradigma de belleza emprendida a partir de este hecho: la etnia de Quetza no tiene la característica nariz ancha que es considerada como más bella de acuerdo a los cánones aztecas y eso le causa un gran sufrimiento: “Tenía la sonrisa generosa, pero la nariz era demasiado pequeña e insignificante. Quetza se lamentaba de no ser dueño de una nariz prominente, de fosas dilatadas y aletas amplias como les gustaba a las mujeres. Suponía que ése era el motivo por el cual Ixaya nunca se había fijado en él más que como un gran amigo" (ANDAHAZI, 2006, p. 44). 


\section{Diego Eduardo Niemetz}

\section{Referencias}

AÍNSA, Fernando. Reescribir el pasado. Mérida-Venezuela: CELARG, 2003.

ANDAHAZI, Federico. El conquitador. Buenos Aires: Ed. Planeta, 2006.

ARACIL VARÓN, María Beatriz. Abel Posse: de la crónica al mito de América. Universidad de Alicante-Servicio de publicaciones: 2004.

BAJTÍN, Mijail. Problemas de la poética de Dostoievski. México D.F.: Fondo de Cultura Económica, 1986.

BARRIENTOS, Juan José. Reynaldo Arenas, Alejo Carpentier y la nueva novela histórica hispanoamericana. En: DOMÍNGUEZ, Mignon (Coord.). Historia, ficción y metaficción en la novela latinoamericana contemporánea. Buenos Aires: Corregidor, 1996. p. 49-67.

BOURDIEU, Pierre. Las reglas del arte: génesis y estructura del campo literario. Barcelona: Anagrama, 1995.

1997. . Razones prácticas. Sobre la teoría de la acción. Barcelona: Anagrama,

CARPENTIER, Alejo. El arpa y la sombra. México: Siglo XXI, 2004.

DI GERÓNIMO, Miriam. La reescritura de la historia: la epopeya nacional borgeana. En: Actas del I Congreso Internacional de Estudios sobre la Épica: Configuraciones del género desde los clásicos a la actualidad. Mendoza, Facultad de Filosofía y Letras. Universidad Nacional de Cuyo. (En prensa).

FERNÁNDEZ PRIETO, Celia. Historia y novela: poética de la novela histórica. Navarra, Eunsa, 1998.

GOIC, Cedomil et al. La novela hispanoamericana: Descubrimiento e invención de América. Valparaíso: Ediciones Universitarias de Valparaíso, 1973.

HUTCHEON, Linda. Irony, Nostalgia, and the Postmodern. Disponible en: <http:// www.library.utoronto.ca/utel/criticism/hutchinp.html>. Acceso: 28 mayo 2012.

. A theory of parody: the teachings of twentieth-century art forms. Urbana and Chicago: University of Illinois Press, 2000.

. La política de la parodia postmoderna. Criterios. Edición especial de homenaje a Bajtín, 1993, p. 187-203.

JAMESON, Frederic. El posmodernismo o la lógica cultural del capitalismo avanzado. Barcelona: Paidós, 1995.

Anos 90, Porto Alegre, v. 21, n. 40, p. 425-462, dez. 2014 
A la busca del colón perdido: modulaciones en torno...

JARA, Sandra. Itinerario hacia la teoría literaria posmoderna: sobre lo impensado del sujeto del lenguaje. En: PIÑA, Cristina (Ed.). Literatura y (pos) modernidad: teorías y lecturas críticas. Buenos Aires: Biblos, 2008. p. 13-53.

JITRIK, Noé. Historia e imaginación literaria: las posibilidades de un género. Buenos Aires: Biblos, 1995.

LUKÁCS, Georg. La novela histórica. México: Era, 1966.

MENTON, Seymour. La nueva novela bistórica de la América Latina, 1979-1992. México: FCE, 1993.

PONS, María Cristina. El secreto de la historia y el regreso de la novela histórica. En: DRUCAROFF, Elsa. Historia Crítica de la literatura argentina. v. 11. La narración gana la partida. Buenos Aires: Emecé, 2000. p. 97-116.

POSSE, Abel. Los perros del paraíso. Barcelona: Argos Vergara, 1983.

SARMIENTO, Alicia. La reescritura de la Historia en la novela hispanoamericana contemporánea. Revista de Literaturas Modernas, n. 22, 1989. p. 227-37.

. Para cambiar la memoria de los hombres. El descubrimiento de América en la novela hispanoamericana contemporánea. AA/VV. 500 años de Hispanoamérica. Conferencias. Mendoza: Edit. de la Facultad de Filosofia y Letras, U.N.Cuyo, 1992. p. 183-211.

SHAW, Donald. Nueva narrativa hispanoamericana: Boom. Posboom. Posmodernismo. Madrid: Cátedra, 1999.

TODOROV, Tzvetan. La conquista de América: el problema del otro. México: Siglo XXI Editores, 1998.

WHITE, Hayden. El contenido de la forma: Narrativa, discurso y representación histórica. Barcelona: Ediciones Paidós, 1992.

. Ficción histórica, historia ficcional y realidad histórica. Buenos Aires: Prometeo, 2010.

Recebido em: 14/05/2014

Aprovado em: 06/08/2014

Anos 90, Porto Alegre, v. 21, n. 40, p. 425-462, dez. 2014 